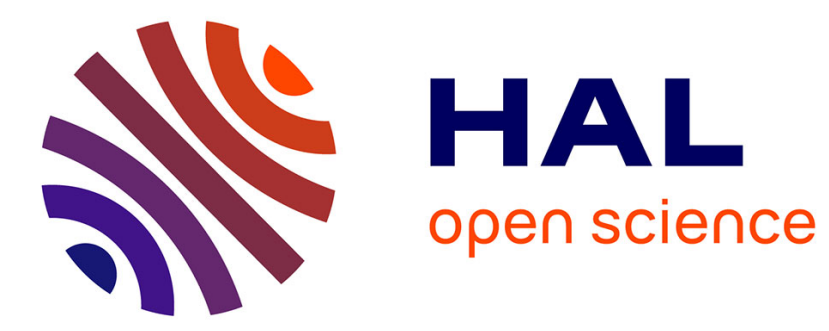

\title{
Improving the heterointerface in hybrid organic-inorganic perovskite solar cells by surface engineering: Insights from periodic hybrid density functional theory calculations

\author{
Jun Su, Tao Zhu, Thierry Pauporté, Ilaria Ciofini, Frédéric Labat
}

\section{To cite this version:}

Jun Su, Tao Zhu, Thierry Pauporté, Ilaria Ciofini, Frédéric Labat. Improving the heterointerface in hybrid organic-inorganic perovskite solar cells by surface engineering: Insights from periodic hybrid density functional theory calculations. Journal of Computational Chemistry, 2020, 41 (19), pp.17401747. 10.1002/jcc.26215 . hal-02999494

\author{
HAL Id: hal-02999494 \\ https://hal.science/hal-02999494
}

Submitted on 10 Nov 2020

HAL is a multi-disciplinary open access archive for the deposit and dissemination of scientific research documents, whether they are published or not. The documents may come from teaching and research institutions in France or abroad, or from public or private research centers.
L'archive ouverte pluridisciplinaire HAL, est destinée au dépôt et à la diffusion de documents scientifiques de niveau recherche, publiés ou non, émanant des établissements d'enseignement et de recherche français ou étrangers, des laboratoires publics ou privés. 
Please cite this paper as:

Jun $\mathrm{Su}^{1}$, Tao $\mathrm{Zhu}^{2}$, Thierry Pauporté ${ }^{2}$, Ilaria Ciofini ${ }^{1}$, Frédéric Labat ${ }^{* 1}$

Improving the Heterointerface in Hybrid Organic-Inorganic Perovskite Solar Cells by Surface Engineering: Insights from Periodic Hybrid Density Functional Theory Calculations

J Comput Chem. (2020) 41,1740-1747. DOI: 10.1002/jcc.26215

': Chimie ParisTech, PSL University, CNRS, Institute of Chemistry for Life and Health Sciences, Chemical Theory and Modelling Group, F-75005 Paris, France.

2: Chimie ParisTech, PSL University, CNRS, Institut de Recherche de Chimie Paris (IRCP), 11 rue P. et M. Curie, F-75005 Paris, France

*frederic.labat@chimie-paristech.fr

\begin{abstract}
:
A periodic hybrid density functional theory computational strategy is presented to model the heterointerface between the methylammonium lead iodide (MAPI) perovskite and titanium dioxide $\left(\mathrm{TiO}_{2}\right)$, as found in perovskite solar cells (PSC), where the 4-chlorobenzoic acid (CBA) ligand is used to improve the stability and the band alignment at the interface. The CBA ligand acts as a bifunctional linker to efficiently connect the perovskite and the oxide moieties, ensuring the stability of the interface through $\mathrm{Ti}-\mathrm{O}$ and $\mathrm{Pb}-\mathrm{Cl}$ interactions. The computed density of states reveals that the perovskite contributes to the top of the valence band while the oxide contributes to the bottom of the conduction band with a direct bandgap of $2.16 \mathrm{eV}$, indicating a possible electron transfer from MAPI to $\mathrm{TiO}_{2}$. Dipole moment analysis additionally reveals that the CBA ligand can induce a favorable effect to improve band alignment and thus electron transfer from MAPI to $\mathrm{TiO}_{2}$. This latter has been quantified by calculation of the spin density of the reduced MAPI/CBA/TiO 2 system and indicates an almost quantitative (99.94\%) electron transfer from MAPI to $\mathrm{TiO}_{2}$ for the surface engineered system, together with an ultrafast electron injection time in the femtosecond timescale. Overall, the proposed DFT-based computational protocol therefore indicates that surface engineering and the use of a bifunctional linker can lead to a better stability, together with improved band alignment and electron injection in PSC systems.
\end{abstract}




\section{INTRODUCTION}

With excellent optoelectronic properties and potential for low-temperature device fabrication, organometal halide perovskites $\left(\mathrm{AMX}_{3}\right)$ are extensively studied materials. ${ }^{1}$ Since their very first combination with mesoporous $\mathrm{TiO}_{2}$ photoanode for visible-light conversion in photovoltaic cells by Myasaka et al. ${ }^{2}$, organometal halide perovskites $\mathrm{AMX}_{3}$ have attracted considerable attention as efficient light harvesters. In particular, organic-inorganic hybrid perovskite solar cells (PSC) have appeared as excellent potential candidates to produce clean energy, with easy fabrication, long charge carrier diffusion lengths and lifetimes, high absorption coefficient, solution processability and high photoconversion efficiencies (PCE). ${ }^{3-20}$

These perovskites are composed of an organic cation $\mathrm{A}$, a divalent metal cation $\mathrm{M}$ generally belonging to the fourth main group and a halide anion $\mathrm{X}$, which are arranged in a rigid threedimensional network of corner-sharing $\mathrm{MX}_{6}$ octohedra. By varying the different possible combinations between these cationic and anionic species, bandgap tuning of the perovskite material is possible, thus allowing to readily modulate its light absorption for photovoltaic application. Although the M and X species can in principle be easily tuned in these structures, the A cation on the other hand fills the 12-fold coordinated cubo-octahedral space created by the inorganic metal halide octahedra, hence making its choice limited to either monovalent cations such as $\mathrm{Cs}^{+}, \mathrm{Rb}^{+}$or $\mathrm{K}^{+}$, or to the small organic methylammonium $\left(\mathrm{MA}^{+}\right)$and formanidinium $\left(\mathrm{FA}^{+}\right)$ions. ${ }^{16}$ In particular, among the most studied hybrid perovskites for PSC application, the pioneering methylammonium lead iodide hybrid perovskite $\left(\mathrm{MAPbI}_{3}\right.$, referred to as MAPI) still remains actively considered nowadays. ${ }^{2,7,21}$

In a PSC, the perovskite layer ${ }^{22}$ ensures light absorption and generates electron-hole charge carrier pairs which then dissociate into free charge carriers. The free excited electrons and holes diffuse within electron and hole transport layers (ETL and HTL) and are then collected by corresponding electrodes. ${ }^{16}$ By optimizing the different components of PSC as well as by finely tuning their combination, their PCE has increased from $3.8^{2}$ to $25.2 \%{ }^{23}$ during the last decade. ${ }^{5,7-15}$ Although PSCs are then now generally considered as one of the most promising devices for photovoltaic energy production, several points still remain critical however for realworld application, including mainly toxicity and long-term stability. For example, MAPI hydrolyzes in the presence of water, breaking the weak interaction between the inorganic and organic networks. ${ }^{24-26}$ In addition, the commonly-used organic HTL for high PCE such as spiro-

OMeTAD, P3HT or PTAA are expensive and sensitive to humidity, ${ }^{27-29}$ and various alternatives such as transition-metal oxides or copper compounds have been explored. ${ }^{30-34}$ The choice of the HTL and ETL is also critical for cell performances, since PSC rely on different interfaces which should all be adequately designed and matched to achieve high PCE, by reducing charge recombination losses and maximizing the open-circuit voltage, ${ }^{35}$ hence implementing 
interfacial and surface engineering is particularly important in these systems. ${ }^{16,36}$ One general possible strategy for surface engineering is the use of facile solution-based processes considering self-assembled monolayers (SAMs) of organic molecules ${ }^{37-39}$ which can form thin, dense and stable layers able to modify the electronic structure of the metal oxide surface they are chemically attached to. In the PSC field, SAMs have already been proposed since they can potentially induce various favorable effects such as morphology modification, band alignment with the energy level of the photoexcited active layer, trap passivation and delay of charge recombination. ${ }^{40,41}$

Among the available modeling tools, density functional theory (DFT) has already been widely used and shown to be a useful tool to predict the structural and electronic properties of key interfaces found in sensitized solar cells, ${ }^{42-51}$ including the one formed between the MAPI perovskite and $\mathrm{TiO}_{2}$ in PSC. ${ }^{52-55}$ While the works devoted to the investigation of the isolated components of this interface are numerous, ${ }^{56-59}$ much fewer have focused on the investigation of the full interface, probably due to its complexity and to the associated high computational cost. For example, Yoshitaka et al. recently investigated the structural stability and the electronic structures of a series of low-indices surfaces of tetragonal MAPI, highlighting that the (110) and (001) terminations are expected to be stable, with shallow surface states that can act as efficient intermediates for hole transport to HTL.$^{60,61}$ The tetragonal MAPI (001) surface was also recently investigated, comparing the two possible $\mathrm{MAI}$ and $\mathrm{PbI}_{2}$ terminations, indicating that the MAI termination is relatively more favorable than the $\mathrm{PbI}_{2}$ one in equilibrium growth. ${ }^{62}$ On the other hand, for the $\mathrm{ETL}, \mathrm{TiO}_{2}$ is usually considered due to its wide bandgap and fairly transparent nature. ${ }^{63}$ Although the rutile polymorph is the most stable one for large particles, nanoparticles preferentially form with the anatase variant which is commonly used in photovoltaic materials. ${ }^{64,65}$ More precisely, the anatase (101) surface is thought to be the most stable surface orientation in such systems. ${ }^{66-69}$ Finally, among the works devoted to the modeling of the full MAPI/TiO ${ }_{2}$ interface, ${ }^{45,50,53,70-72}$ De Angelis ${ }^{53}$ et al. proposed the (110) surface of MAPI to preferentially grow on $\mathrm{TiO}_{2}$ due to better lattice matching, with the chloride atoms concentrating at the $\mathrm{TiO}_{2}$ interface. ${ }^{70}$

In this article, we present a theoretical investigation of a modified $\mathrm{MAPI} / \mathrm{TiO}_{2}$ interface that was first optimized experimentally. Indeed, we have studied the effect of SAMs of a series of para-substituted benzoic acid derivatives as $\mathrm{TiO}_{2} /$ perovskite interfacial modifiers. ${ }^{41}$ Among them, we have found that 4-chlorobenzoic acid (CBA) was the best candidate which improves markedly the power conversion efficiency (PCE) of the solar cells. Interfacial engineering with CBA enabled us to achieve a PCE of $21.3 \%$ to be compared to $20.3 \%$ for the untreated cells (see Tables S1 and S2, Supporting Information). However, while interfaces play a key role in such cells, their experimental characterization at the structural and electronic levels still remains 
difficult. Consequently, modeling of such interfaces with appropriate computational methods is relevant for a better understanding of the basic working principles of PSC, and thus for the design of novel systems. We show here that the linking of perovskite and $\mathrm{TiO}_{2}$ moieties is enhanced by using the bifunctional CBA ligand. A model of the MAPI/CBA/TiO ${ }_{2}$ interface (Figure 1) has been built and its structural and electronic properties have been fully characterized at the periodic hybrid DFT level. The key electron injection process found at this interface has also been addressed. We show that SAMs can be efficiently used for surface engineering of the heterointerface found in PSC between MAPI and $\mathrm{TiO}_{2}$, due its bifunctional nature, acting both as a suitable spacer at the interface to improve its stability, but also imposing a favorable dipole moment to improve band alignment and thus electron injection in such systems.

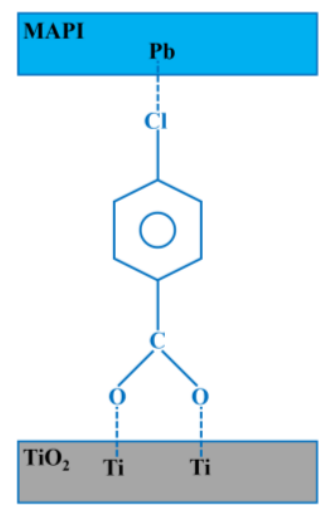

Figure 1: Schematic of the MAPI/CBA/TiO 2 interface.

In the discussion, computational details are first presented in Section 2 while results obtained are discussed in Section 3. Finally, some conclusions are drawn in Section 4.

\section{COMPUTATIONAL DETAILS}

All calculations were carried out with the periodic Crystal17 code, which is based on a linear combination of atom-centered Gaussian orbitals and solves self-consistently both Hartree-Fock (HF) and Kohn-Sham equations. ${ }^{73-75}$ Exchange and correlation energies were described using the global hybrid PBE0 functional, containing $25 \%$ of HF exchange. ${ }^{76}$ Previous studies have shown that this functional can indeed provide reliable geometric and electronic properties of both $\mathrm{TiO}_{2}{ }^{77}$ and $\mathrm{MAPI}^{46}$, that are the two building blocks of the interface targeted. Additional dispersion effects were accounted for through the empirical D3 correction. ${ }^{78}$ Allelectron basis sets have been used for the CBA ligand and the methylammonium $\left(\mathrm{MA}^{+}\right)$ moieties. More precisely, for MA atoms, (31/1) contractions were used for $\mathrm{H}$, while (631/31/1) contractions were employed for both $\mathrm{C}$ and $\mathrm{N}$ atoms. For CBA atoms, (511/1), (621/21/1), (7311/311/1), (8411/411/1) and (86311/6311) contractions were considered for H, C, N, O and $\mathrm{Cl}$ atoms, respectively. On the other hand, pseudopotentials were considered for all the other atoms. For Ti and $\mathrm{O}$ of $\mathrm{TiO}_{2}$, Durand and Barthelat large-core pseudopotentials with associated 
(1/1/41) and (31/31) contractions corresponding to 4 and 6 explicit electrons, respectively, were chosen. ${ }^{79,80}$ Finally, for $\mathrm{Pb}$ and I, small core fully relativistic pseudopotentials developed at the Stuttgart University were selected, with 22 explicit electrons described using a (8811/1188/611/1) contraction scheme for $\mathrm{Pb}$, and 25 explicit electrons described using a (8811/661/61) contraction scheme for I. ${ }^{81}$

Reciprocal space was sampled using a shrinking factor of 2, corresponding to $4 \mathbf{k}$ points in the irreducible Brillouin zone. Numerical DFT integration was performed considering 99 radial points and 1454 angular points, ensuring an error on the integrated electron density lower than $10^{-5}$ |e-| per unit cell. The Coulomb and exchange series were truncated with threshold values of $10^{-7}, 10^{-7}, 10^{-7}, 10^{-9}$, and $10^{-27}$.

Cell parameters of the lattice as well as atomic positions of a selected fragment of atoms (see below) were relaxed during geometry optimizations. Convergence was determined from the root-mean-square and absolute value of the largest component of the forces and displacements, considering default values. ${ }^{75}$

Interface formation was energetically characterized by considering two quantities:

- adhesion energy, which is the energy gained by forming the interface, computed as:

$E_{\mathrm{ads}}=E(\mathrm{MAPI} / \mathrm{CBA})+E\left(\mathrm{TiO}_{2}\right)-E\left(\mathrm{MAPI} / \mathrm{CBA} / \mathrm{TiO}_{2}\right)$

where $E(\mathrm{MAPI} / \mathrm{CBA})$ and $E\left(\mathrm{TiO}_{2}\right)$ are the total energies of the optimized MAPI/CBA slab and $\mathrm{TiO}_{2}$ supercell slab models, respectively, and $E\left(\mathrm{MAPI} / \mathrm{CBA} / \mathrm{TiO}_{2}\right)$ is the total energy of the $\mathrm{MAPI} / \mathrm{CBA} / \mathrm{TiO}_{2}$ interface

- specific adhesion energy, which is the adhesion energy per unit surface area, calculated as:

$$
\beta_{\mathrm{ads}}=E_{\mathrm{ads}} / \mathrm{S}
$$

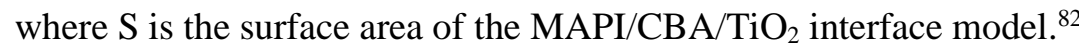

The electron injection time was evaluated by considering a simplified orbital-based model derived from the original Newns-Anderson proposal for adsorbates on surfaces ${ }^{83}$, which was already successfully applied to dye-sensitized solar cells ${ }^{51,84}$. In this approach, only the evaluation of the broadening $(\Delta$, in $\mathrm{meV}$ ) of the donor level of the perovskite sensitizer when it is adsorbed on the $\mathrm{TiO}_{2}$ surface is required to compute the injection time ( $\tau$, in fs) according to:

$\tau=658 / \Delta$

More details regarding this methodology are available in Ref. 85 for instance. ${ }^{85}$ 


\section{RESULTS AND DISCUSSION}

\section{The models:}

A MAPI/CBA/TiO 2 interface was built starting from converged surface models of its two building blocks: the $\mathrm{TiO}_{2}$ oxide and the MAPI perovskite. A $(2 \times 2)$ supercell model of the anatase $\mathrm{TiO}_{2}-(101)$ surface with 8 layers, corresponding to $8 \mathrm{O}$-Ti-O trilayers with 96 atoms and lattice parameters $a=14.981 \AA, b=11.088 \AA$ and $\gamma=109.7^{\circ}$ was selected for the oxide part. For MAPI, although both MAI- and $\mathrm{PbI}_{2}$-terminated (110) surfaces can exist, the former is known to be stable ${ }^{61}$ and is expected to more easily bind to the $\mathrm{TiO}_{2}$ surface than the latter. A 3- $\mathrm{PbI}_{2}$ layers (110) slab was therefore obtained from the tetragonal MAPI bulk system with space group $I_{4} / \mathrm{mcm}$, resulting in a 2D lattice with lattice parameters $a, b$ and $\gamma$ of $12.343 \AA$, $12.555 \AA$ and $90.0^{\circ}$, respectively. Consequently, a large mismatch between the lattice parameters of the 2D lattices of the $\mathrm{TiO}_{2}$ and MAPI slabs was obtained. The bifunctional nature of the CBA ligand was exploited by considering its carboxylate part to bind to $\mathrm{TiO}_{2}$ in a bridging bidentate mode, while its $\mathrm{Cl}$ atom was oriented towards the $\mathrm{Pb}$ atoms of MAPI close to the $\mathrm{TiO}_{2}$ substrate. By substituting all $\mathrm{I}^{-}$of the last layer of the MAPI surface with $\mathrm{Cl}$ atoms, $\mathrm{Pb}-\mathrm{Cl}$ bonds were then created and the charge neutrality of the resulting unit cell was ensured by removing all $\mathrm{H}^{+}$of the last layer of MA moieties of MAPI. The final interface model was obtained by modifying the MAPI slab lattice to the values of the $\mathrm{TiO}_{2}$ supercell, resulting in an interface model with P1 symmetry, 328 atoms and 3876 atomic orbitals per unit cell. The lattice was then fully-relaxed, and all atoms but the lower 6 bottom layers of the $\mathrm{TiO}_{2}$ substrate were allowed to relax. In addition, to more clearly highlight the role of the $\mathrm{TiO}_{2}$ substrate in the $\mathrm{MAPI} / \mathrm{CBA} / \mathrm{TiO}_{2}$ interface, and especially on its electronic properties, we also considered adsorption of CBA on a MAI-terminated MAPI (110) slab with 3-PbI ${ }_{2}$ layers, considering a 1:1 substitution ratio between $\mathrm{I}^{-}$and $\mathrm{Cl}$ atoms. We note here that the $\mathrm{CH}_{3} \mathrm{NH}_{2}$ layer formed in contact with the CBA ligands is relevant for PSC application, since the $\mathrm{CH}_{3} \mathrm{NH}_{3}{ }^{+}$ion in MAPI is well-known to readily deprotonate in the presence of water. In addition, chlorine atoms have already been shown to tend to concentrate at the $\mathrm{TiO}_{2}$ interface. ${ }^{71}$

Figures $2 \mathbf{c}$ and $\mathbf{2 d}$ present resulting structures of both models after geometry optimization.

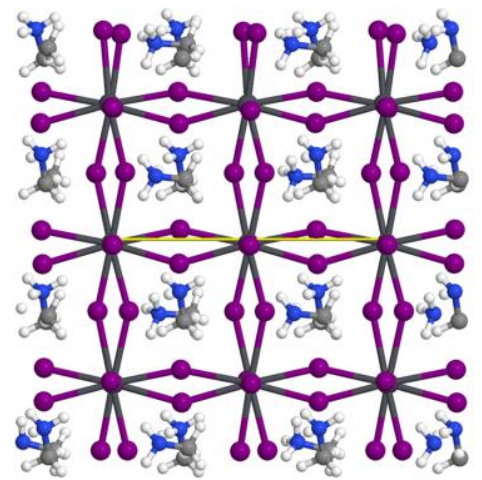

(a)

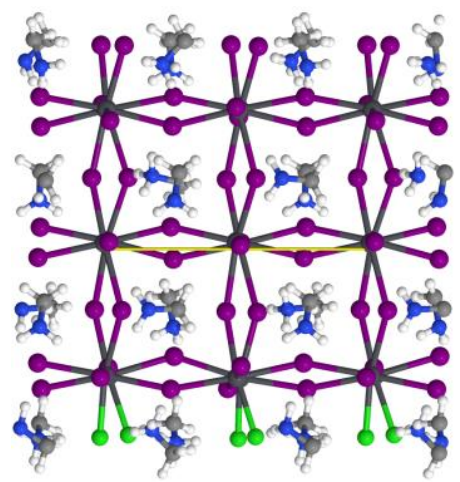

(b) 


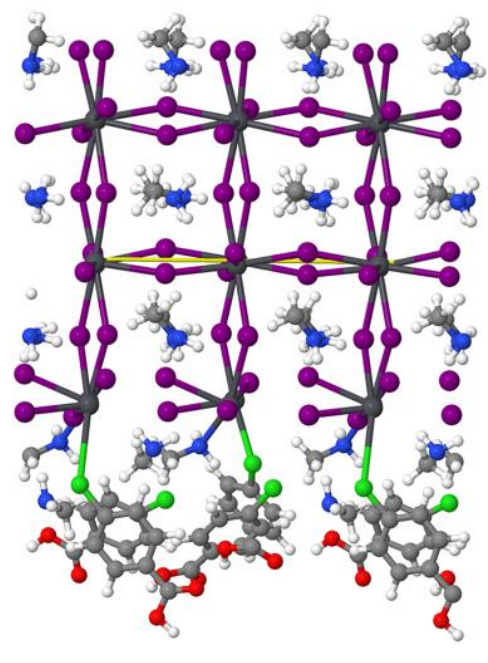

(c)

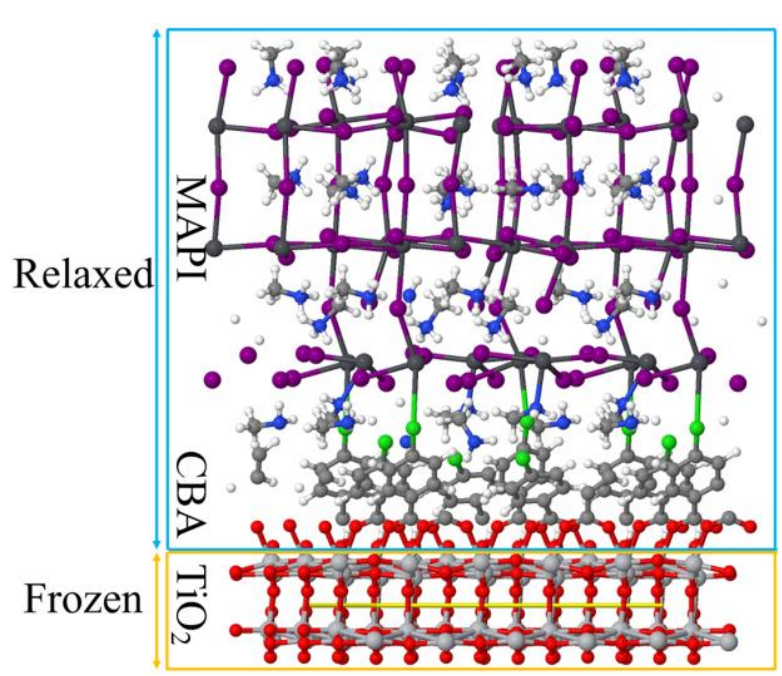

(d)

Figure 2: Ball and stick representation of the (a) MAPI(110) surface, (b) the MAPI-slab with all iodide atoms on one surface replaced by chloride atoms, (c) MAPI/CBA unit cell and (d) $\mathrm{MAPI} / \mathrm{CBA} / \mathrm{TiO}_{2}$ interface unit cell. The solid yellow line represents the unit cell. Red, light grey, white, green, purple, dark grey, blue and grey spheres correspond to $\mathrm{O}, \mathrm{Ti}, \mathrm{H}, \mathrm{Cl}, \mathrm{I}, \mathrm{Pb}, \mathrm{N}$ and $\mathrm{C}$ atoms, respectively. The relaxed and frozen parts considered for the geometry optimization of the MAPI/CBA/ $\mathrm{TiO}_{2}$ interface are indicated in Figure 2(d).

\section{Structural and energetic features:}

Table 1 summarizes the main structural features of the optimized lattices of the different building blocks and interface models considered, while Table 2 reports selected resulting distances.

The optimized $a$ and $b$ cell parameters of the MAPI/CBA/TiO 2 interface model are close to those of the $\mathrm{TiO}_{2}$ supercell considered, with values of $14.821 \AA$ and $11.003 \AA$, together with a $\gamma$ angle of $108.0^{\circ}$. Compared to the $\mathrm{TiO}_{2}$ supercell lattice, a small shrinking of all lattice parameters is therefore obtained when going from the $\mathrm{TiO}_{2}$ supercell to the MAPI/CBA/TiO 2 interface, with shrinking values of $-1.07,-0.77$ and $-1.55 \%$, respectively for the $a, b$ and $\gamma$ parameters. From the data reported in Table 2, both Ti-O and $\mathrm{Pb}-\mathrm{Cl}$ bonds can be evidenced, the CBA ligand acting with two complementary features to ensure interface stability between the perovskite and the oxide. The first feature corresponds to its bifunctional linker nature: a bridging bidentate mode is involved between the CBA carboxylate moiety and $\mathrm{TiO}_{2}$, while strongly distorted $\mathrm{PbI}_{5} \mathrm{Cl}$ octohedra can be evidenced between MAPI and CBA. Here, we note that $\mathrm{Pb}$ atoms both interact with $\mathrm{Cl}$ atoms and the deprotonated $\mathrm{CH}_{3} \mathrm{NH}_{3}{ }^{+}$groups in the layer in contact with CBA. The same conclusion can be drawn in the MAPI/CBA case. The second feature is the ability of CBA ligands to lay on the $\mathrm{TiO}_{2}$ substrate, with computed tilting angles with respect to the surface normal of $30.0,38.6,38.6$ and $46.9^{\circ}$ for the four CBA molecules of the MAPI/CBA/TiO 2 interface model unit cell for instance. In particular, favorable $\mathrm{H}^{+} / \pi$ interactions between the dissociated $\mathrm{H}^{+}$of the carboxylate groups of CBA adsorbed on the $\mathrm{TiO}_{2}$ 
substrate and the benzene ring of the CBA ligands tend to further improve interface stability by building a favorably organized $\mathrm{CBA}-\mathrm{TiO}_{2}$ interface for the binding of MAPI. This can be related to the rigid nature of the CBA ligand. The computed adhesion energy of the $\mathrm{MAPI} / \mathrm{CBA} / \mathrm{TiO}_{2}$ model further confirms these conclusions, with a computed value of $3.45 \mathrm{eV}$, corresponding to a specific adhesion energy of $0.02 \mathrm{eV} / \AA^{2}$, indicating a stable interface formation. We note that this value is in line with the $0.04 \mathrm{eV} / \AA^{2}$ value recently reported by Mosconi et al. for a similar interface based on the same surface orientations, ${ }^{70}$ as well with those obtained with other orientations. ${ }^{72}$

Table 1: Lattice parameters $a, b$ (in $\AA$ ) and $\gamma$ (in degrees) as well as computed band gaps ( $E_{\mathrm{g}}$, in $\mathrm{eV}$ ) for selected systems involved in the interface model construction. Adhesion energy ( $E_{\text {adh }}$, in $\mathrm{eV})$ and specific adhesion energy $\left(\beta\right.$, in $\left.\mathrm{eV} \cdot \AA^{-2}\right)$ of the MAPI/CBA/TiO 2 interface are also given.

\begin{tabular}{lcccc}
\hline & MAPI (110) & CBA/MAPI (110) & $\begin{array}{c}\mathrm{TiO}_{2} \\
(101)\end{array}$ & $\begin{array}{c}\text { MAPI (110)/CBA/ } / \mathrm{TiO}_{2} \\
(101)\end{array}$ \\
\hline$a$ & 12.343 & 12.343 & 14.981 & 14.821 \\
$b$ & 12.555 & 12.555 & 11.088 & 11.003 \\
$\gamma$ & 90.00 & 90.00 & 109.74 & 108.03 \\
\hline$E_{\mathrm{g}}$ & 2.97 & 3.39 & 5.03 & 2.16 \\
$E_{\mathrm{ad}}$ & -- & -- & -- & 3.45 \\
$\beta$ & -- & -- & -- & 0.02 \\
\hline
\end{tabular}

Table 2: Selected distances (in $\AA$ ) between $\mathrm{Pb}, \mathrm{N}$ and $\mathrm{Cl}$ atoms of the MAPI/CBA and $\mathrm{MAPI} / \mathrm{CBA} / \mathrm{TiO}_{2}$ systems.

\begin{tabular}{lllllllllll}
\hline & $\mathrm{d}_{\mathrm{N} / \mathrm{Pb}}$ & \multicolumn{1}{c}{$\mathrm{d}_{\mathrm{Cl} / \mathrm{Pb}}$} & \multicolumn{5}{c}{$\mathrm{d}_{\mathrm{Ti} / \mathrm{O}}$} \\
\hline MAPI/CBA & 3.35 & 3.71 & 4.03 & 5.47 & 2.62 & 2.63 & 4.74 & 5.56 & - & - \\
& 8 & 0 & 2 & 2 & 7 & 2 & 9 & 6 & & \\
MAPI/CBA/TiO & 3.45 & 3.95 & 4.68 & 5.42 & 2.51 & 2.55 & 5.06 & 5.66 & 2.17 & 2.10 \\
2 & 7 & 7 & 6 & 4 & 7 & 3 & 3 & 9 & 6 & 0 \\
\hline
\end{tabular}

\section{Electronic properties:}

Figure 3 presents the computed band structures, as well as the total and projected density of states (TDOS and PDOS) of the MAPI/CBA/TiO 2 and MAPI/CBA interfaces.

For MAPI/CBA, band dispersion can be noticed at the top of the valence band (VB) and at the bottom of the conduction band (CB). This can be related to the interaction of the CBA ligand with MAPI through its $\mathrm{Cl}$ atoms. In addition, the top of the VB and the bottom of the $\mathrm{CB}$ are mainly composed by the MAPI perovskite in which $\mathrm{I}^{-}$has been substituted with $\mathrm{Cl}$ in a 1:1 ratio. Compared to the clean MAPI (110) surface therefore, this leads to a band gap increase 
from 2.97 to $3.39 \mathrm{eV}$. When considering the MAPI/CBA/TiO ${ }_{2}$ interface on the other hand, the band gap decreases to $2.16 \mathrm{eV}$ mainly due to the $\mathrm{TiO}_{2}$ contribution at the bottom of the $\mathrm{CB}$. In fact, the band structure and DOS analysis of the MAPI/CBA/TiO ${ }_{2}$ interface reveals that the top of the $\mathrm{VB}$ is mainly due to MAPI while the bottom of the $\mathrm{CB}$ is mainly due to $\mathrm{TiO}_{2}$, suggesting a possible electron transfer from the perovskite to the oxide from an energetic viewpoint, which is in line with the working principles of PSC mentioned above. Furthermore, it should be noted that the CBA ligand does not contribute to the valence or conduction bands close to the band gap region. Here, we note that no spin-orbit coupling effects have been taken into account in these calculations, but these have previously been quantified and shown to further reduce the above-mentioned band gap values of about $1.1 \mathrm{eV}^{46}$

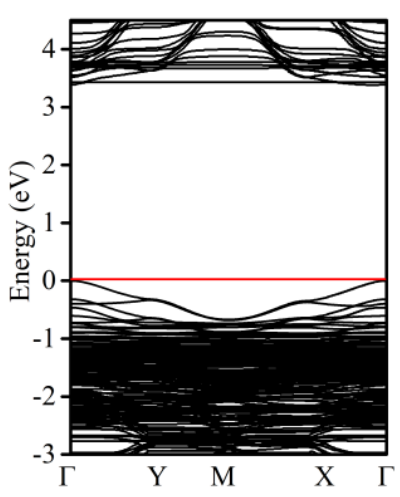

(a)



(c)

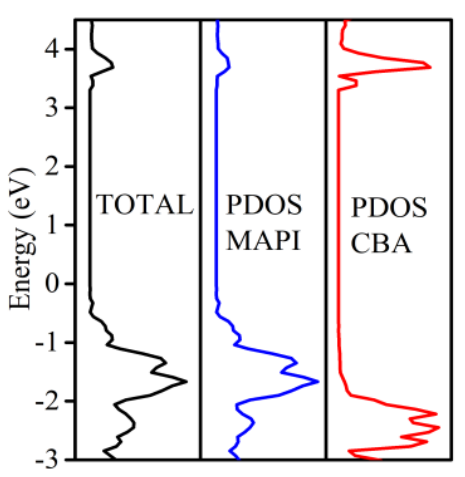

(b)

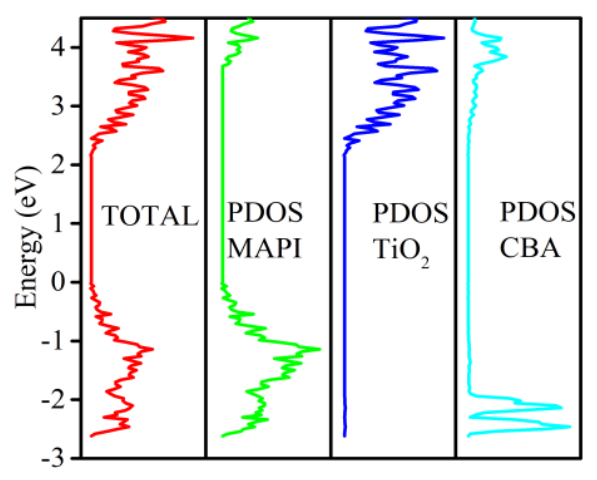

(d)

Figure 3: (left) Band structure and (right) total and projected density of states (TDOS and PDOS) of the (top) MAPI/CBA and (bottom) MAPI/CBA/TiO 2 interfaces. k-points used for the band structure are: $\Gamma(0,0,0), \mathrm{Y}(0,1 / 2,0), \mathrm{M}(1 / 2,1 / 2,0)$ and $\mathrm{X}(1 / 2,0,0)$.

Furthermore, both band structures present direct band gaps at $\Gamma$, highlighting a possible favorable and efficient photoexcitation of the heterointerface.

Band edge movements upon interface creation can also be qualitatively rationalized from the dipole moments components along the normal direction to the surface plane of the interface according to the Poisson equation ${ }^{41}$ : 


$$
\Delta \mathrm{V}=\frac{N_{s} \mu \cos \theta_{a}}{\varepsilon_{r} \varepsilon_{0}}
$$

where $N_{\mathrm{s}}$ is the surface dipole density, $\mu$ the dipole moment, $\theta_{\mathrm{a}}$ the tilt angle of the dipole with respect to the surface normal. $\varepsilon_{\mathrm{r}}$ is the dielectric constant, and $\varepsilon_{0}$ is the permittivity of free space. A step in the local vacuum level $\Delta \mathrm{V}$ can be obtained and $\mathrm{q} \Delta \mathrm{V}$, with $\mathrm{q}$ the elementary charge, can then modify the work function and the band edges of the interface. In particular, a positive value of $\Delta \mathrm{V}$ would enhance the charge transfer to $\mathrm{TiO}_{2}$ while a negative one would reduce it. From the values reported in Table 3, for $\mathrm{CBA} / \mathrm{TiO}_{2}$, the positive value suggests a charge transfer to the $\mathrm{TiO}_{2}$ surface. ${ }^{41}$ As for MAPI/CBA, the value of the dipole moment pointing towards MAPI in the chemistry notation is negative, indicating that CBA may block electron reflow to MAPI. Furthermore, it can be noticed that a positive value is also obtained for $\mathrm{MAPI} / \mathrm{CBA} / \mathrm{TiO}_{2}$, thus highlighting that $\mathrm{CBA}$ can potentially enhance the electron transfer from MAPI to $\mathrm{TiO}_{2}$.

Table 3: Dipole moments components along the surface normals ( $\mu_{\mathrm{z}}$, in Debye) of the $\mathrm{CBA} / \mathrm{TiO}_{2}, \mathrm{MAPI} / \mathrm{CBA}$ and $\mathrm{MAPI} / \mathrm{CBA} / \mathrm{TiO}_{2}$ systems.

\begin{tabular}{lc}
\hline Systems & $\mu_{z}$ \\
\hline $\mathrm{CBA} / \mathrm{TiO}_{2}$ & 0.89 \\
$\mathrm{MAPI} / \mathrm{CBA}$ & -0.88 \\
$\mathrm{MAPI} / \mathrm{CBA} / \mathrm{TiO}_{2}$ & 0.61 \\
\hline
\end{tabular}

To better clarify this point, electron injection from MAPI to $\mathrm{TiO}_{2}$ has been analyzed using an approach that we have developed notably for dye-sensitized solar cells $\mathrm{s}^{42,43}$ and quantum-dot sensitized solar cells ${ }^{44}$. More precisely, the spin density of the reduced MAPI/CBA/TiO ${ }_{2}$ system has been computed and the corresponding isodensity plot is shown in Figure 4. It is clear that the computed spin density is mainly delocalized over the $\mathrm{TiO}_{2}$ part, with a $99.94 \%$ contribution of the added electron on the $\mathrm{TiO}_{2}$ substrate. This value is a quantification of the injection efficiency of the photogenerated electrons and indicates an almost quantitative electron transfer from MAPI to $\mathrm{TiO}_{2}$ through the CBA ligand. 




Figure 4: Spin density of the reduced MAPI-CBA-TiO 2 interface system (excess of alpha electron is indicated in yellow), isosurface contour value: $|0.00271|$ a.u.

Finally, based on the Newns-Anderson model and the computed electronic structure of the $\mathrm{MAPI} / \mathrm{CBA} / \mathrm{TiO}_{2}$ system, the electron injection time is estimated to be $24 \mathrm{fs}$, indicating an ultrafast electron injection. This result is in good agreement with a previously-reported estimate based on a coupling matrix elements approach for the bare $\mathrm{MAPI} / \mathrm{TiO}_{2}$ interface ${ }^{86}$ where an injection in the femtosecond time scale has been obtained. We note that controversial experimental results are available regarding the electron injection time with values reported both in the picosecond ${ }^{87}$ or sub-picosecond ${ }^{88,89}$ timescales, preventing a more rigorous comparison between experimental and computed data.

\section{CONCLUSIONS}

In this article, a periodic hybrid density functional theory computational strategy has been presented to model the heterointerface between the MAPI perovskite and $\mathrm{TiO}_{2}$, as found in PSC, in which the CBA ligand has been used to improve the stability and the band alignment at the interface. The CBA ligand has been selected to act as a bifunctional linker to efficiently link the perovskite and the oxide moieties, ensuring stability of the interface through $\mathrm{Ti}-\mathrm{O}$ and $\mathrm{Pb}-\mathrm{Cl}$ interactions. The computed density of states revealed that the perovskite contributes to the top of the valence band while the oxide contributes to the bottom of the conduction band with a direct bandgap of $2.16 \mathrm{eV}$, indicating a possible electron transfer from $\mathrm{MAPI}$ to $\mathrm{TiO}_{2}$. Dipole moment analysis additionally revealed that the CBA ligand can induce a favorable effect to improve band alignment and thus electron transfer from MAPI to $\mathrm{TiO}_{2}$. This latter has been quantified by calculation of the spin density of the reduced MAPI/CBA/ $/ \mathrm{TiO}_{2}$ system and indicated an almost quantitative electron transfer from MAPI to $\mathrm{TiO}_{2}$ for the surface engineered system, together with an ultrafast injection time in the femtosecond timescale. Overall, the proposed DFT-based computational protocol therefore indicated that by surface engineering 
with a bifunctional linker such as CBA, a better stability, together with improved band alignment and electron injection, could be obtained for PSC systems. Work is in progress to design novel PSC systems with enhanced efficiency based on these guidelines.

\section{ACKNOWLEDGMENTS}

J. S. and T. Z. acknowledge the CSC for Ph.D. scholarship. The authors acknowledge the use of computational resources at Très Grand Centre de Calcul (TGCC) provided by GENCI through project A0050810135. IC and FL thank the ITN program COSINE (Grant agreement ID 765739) for support.

\section{REFERENCES}

1. S. A. Kulkarni, S. G. Mhaisalkar, N. Mathews and P. P. Boix, Small Methods, 2019, 3, 1800231.

2. A. Kojima, K. Teshima, Y. Shirai and T. Miyasaka, J. Am. Chem. Soc., 2009, 131, 6050.

3. P. J. Wang, M. Ulfa and T. Pauporté, J. Phys. Chem. C, 2018, 122, 1973.

4. P. J. Wang, Z. P. Shao, M. Ulfa and T. Pauporté, J. Phys. Chem. C, 2017, 121, 9131.

5. A. Leblanc, N. Mercier, M. Allain, J. Dittmer, V. Fernandez, T. Pauporté, Angew. Chem. Int. Edit., 2017, 56, 16067.

6. J. Zhang, E. J. Juárez-Pérez, I. Mora-Seró, B. Viana and T. Pauporté, J. Mater. Chem. A, 2015, 3, 4909.

7. H.-S. Kim, C.-R. Lee, J.-H. Im, K.-B. Lee, T. Moehl, A. Marchioro, S.-J. Moon, R. Humphry-Baker, J.-H. Yum, J. E. Moser, M. Grätzel and N.-G. Park, Sci. Rep., 2012, 2, 591.

8. M. M. Lee, J. Teuscher, T. Miyasaka, T. N. Murakami and H. J. Snaith, Science, 2012, 338, 643.

9. M. Z. Liu, M. B. Johnston and H. J. Snaith, Nature, 2013, 501, 395.

10. J. Burschka, N. Pellet, S.-J. Moon, R. Humphry-Baker, P. Gao, M. K. Nazeeruddin and M. Grätzel, Nature, 2013, 499, 316.

11. J. Zhang, P. Barboux and T. Pauporté, Adv. Energy Mater., 2014, 4, 1400932.

12. W. Y. Nie, H. Tsai, R. Asadpour, J.-C. Blancon, A. J. Neukirch, G. Gupta, J. J. Crochet, M. Chhowalla, S. Tretiak, M. A. Alam, H.-L. cWang and A. D. Mohite, Science, 2015, 347, 522.

13. J. B. You, L. Meng, T.-B. Song, T.-F. Guo, Y. M. Yang, W.-H. Chang, Z. R. Hong, H. J. Chen, H. P. Zhou, Q. Chen, Y. S. Liu, N. De Marco and Y. Yang, Nature Nanotech., 2016, 11, 75 .

14. W. S. Yang, B.-W. Park, E. H. Jung, N. J. Jeon, Y. C. Kim, D. Uk Lee, S. S. Shin, J. Seo, E. K. Kim, J. H. Noh and S. Il Seok, Science, 2017, 356, 1376.

15. D. W. De Quilettes, S. M. Vorpahl, S. D. Stranks, H. Nagaoka, G. E. Eperon, M. E. Ziffer, H. J. Snaith and D. S. Ginger, Science 2015, 348, 683.

16. P. Gao, M. Grätzel, M. K. Nazeeruddin, Energy \& Environ. Sci., 2014, 7, 2448.

17. Y. X. Chen, B. B. Li, W. Huang, D. Q. Gao and Z. Q. Liang, Chem. Commun., 2015, 51, 11997. 
18. J. H. Heo, D. H. Song, H. J. Han, S. Y. Kim, J. H. Kim, D. Kim, H. W. Shin, T. K. Ahn, C. Wolf, T.-W. Lee and S. H. Im, Adv. Mater., 2015, 27, 3424.

19. J. Seo, S. Park, Y. C. Kim, N. J. Jeon, J. H. Noh, S. C. Yoon and S. Il Seok, Energy \& Environ. Sci., 2014, 7, 2642.

20. T.-Y. Yang, G. Gregori, N. Pellet, M. Grätzel and J. Maier, Angew. Chem.-Int. Edit., 2015, 54, 7905 .

21. J.-H. Im, C.-R. Lee, J.-W. Lee, S.-W. Park and N.-G. Park, Nanoscale, 2011, 3, 4088.

22. M. A. Green, A. Ho-Baillie and H. J. Snaith, Nature Photon., 2014, 8, 506.

23. https://www.nrel.gov/pv/cell-efficiency.html

24. J. M. Frost, K. T. Butler, F. Brivio, C. H. Hendon, M. Van Schilfgaarde and A. Walsh, Nano Lett., 2014, 14, 2584.

25. J. S. Manser, M. I. Saidaminov, J. A. Christians, O. M. Bakr and P. V. Kamat, Accounts Chem. Res., 2016, 49, 330.

26. G. D. Niu, X. D. Guo and L. D. Wang, J. Mater. Chem. A, 2015, 3, 8970.

27. F. Sahli, J. Werner, B. A. Kamino, M. Bräuninger, R. Monnard, B. Paviet-Salomon, L. Barraud, L. Ding, J. J. D. Leon, D. Sacchetto, G. Cattaneo, M. Despeisse, M. Boccard, S. Nicolay, Q. Jeangros, B. Niesen and C. Ballif, Nature Mater., 2018, 17, 820.

28. N. J. Jeon, H. Na, E. H. Jung, T.-Y. Yang, Y. G. Lee, G. Kim, H.-W. Shin, S. Il Seok, J. Lee and J. Seo, Nature Energy, 2018, 3, 682.

29. K. A. Bush, A. F. Palmstrom, J. Y. Zhengshan, M. Boccard, R. Cheacharoen, J. P. Mailoa, D. P. McMeekin, R. L. Z. Hoye, C. D. Bailie, T. Leijtens, P. lan Marius, C. M. Maxmillian, R. Nicholas, P. Rohit, S. Sarah, H. Duncan, M. Wen, M. Farhad, J. S. Henry, B. Tonio, C. H. Zachary, F. B. Stacey and D. M. Michael, Nature Energy, 2017, 2, 17009.

30. J. Urieta-Mora, I. García-Benito, A. Molina-Ontoria and N. Martín, Chem. Soc. Rev., 2018, 47,8541 .

31. L. Calió, S. Kazim, M. Grätzel and S. Ahmad, Angew. Chem.-Int. Edit., 2016, 55, 14522.

32. P.-K. Kung, M.-H. Li, P.-Y. Lin, Y.-H. Chiang, C.-R. Chan, T.-F. Guo and P. Chen, Adv. Mater. Interfaces, 2018, 5, 1800882.

33. Z. Yu and L. C. Sun, Adv. Energy Mater, 2015, 5, 1500213.

34. P. Qin, S. Tanaka, S. Ito, N. Tetreault, K. Manabe, H. Nishino, M. K. Nazeeruddin and M. Grätzel, Nature Commun., 2014, 5, 3834.

35. E. Yalcin, M. Can, C. Rodriguez-Seco, E. Aktas, R. Pudi, W. Cambarau, S. Demic and E. Palomares, Energy \& Environ. Sci., 2019, 12, 230.

36. B. B. Li, Y. N. Chen, Z. Q. Liang, D. Q. Gao and W. Huang, RSC Adv., 2015, 5, 94290.

37. R. Qiao and L. J. Zuo, J. Mater. Res., 2018, 33, 387.

38. T. Hu, T. Becker, N. Pourdavoud, J. Zhao, K. O. Brinkmann, R. Heiderhoff, T. Gahlmann, Z. Q. Huang, S. Olthof, K. Meerholz, D. Többens, B. C. Cheng, Y. W. Chen and T. Riedl, Adv. Mater., 2017, 29, 1606656.

39. S. Olthof and K. Meerholz, Sci. Rep., 2017, 7, 40267.

40. C. Goh, S. R. Scully and M. D. McGehee, J. Appl. Phys., 2007, 101, 114503.

41. T. Zhu, J. Su, J. Alvarez, G. Lefèvre, F. Labat, I. Ciofini and T. Pauporté, Adv. Funct. Mater., 2019, 29, 1903981.

42. T. Le Bahers, T. Pauporté, P. P. Lainé, F. Labat, C. Adamo and I. Ciofini, J. Phys. Chem. Lett., 2013, 4, 1044. 
43. T. Le Bahers, F. Labat, T. Pauporté, P. P. Lainé and I. Ciofini, J. Am. Chem. Soc., 2011, 133, 8005.

44. A. Szemjonov, T. Pauporté, S. Ithurria, S. Pedetti, N. Lequeux, B. Dubertret, I. Ciofini and F. Labat, J. Mater. Chem. A, 2016, 4, 13081.

45. V. Roiati, E. Mosconi, A. Listorti, S. Colella, G. Gigli and F. De Angelis, Nano Lett., 2014, 14, 2168.

46. S. T. A. G. Melissen, F. Labat, P. Sautet and T. Le Bahers, Phys. Chem. Chem. Phys. 2015, 17, 2199.

47. W.-J. Yin, T. T. Shi and Y. F. Yan, Appl. Phys. Lett., 2014, 104, 063903.

48. J. Even, L. Pedesseau, M.-A. Dupertuis, J.-M. Jancu and C. Katan, Phys. Rev. B, 2012, 86, 205301.

49. L. H. Zhang and P. H.-L. Sit, J. Mater. Chem. A, 2017, 5, 23976.

50. F. De Angelis, Accounts Chem. Res., 2014, 47, 3349.

51. F. Labat, T. Le Bahers, I. Ciofini and C. Adamo, Accounts Chem. Res., 2012, 45, 1268.

52. N. Sultana, A. Al Amin, D. Z. Metin and N. Gaston, J. Mater. Sci., 2019, 54, 13594.

53. E. Mosconi, G. Grancini, C. Roldán-Carmona, P. Gratia, I. Zimmermann, M. K. Nazeeruddin and F. De Angelis, Chem. Mater., 2016, 28, 3612.

54. M. Abdi-Jalebi, M. I. Dar, A. Sadhanala, S. P. Senanayak, F. Giordano, S. M. Zakeeruddin, M. Grätzel and R. H. Friend, J. Phys. Chem. Lett., 2016, 7, 3264.

55. R. Lindblad, D. Q. Bi, B.-W. Park, J. Oscarsson, M. Gorgoi, H. Siegbahn, M. Odelius, E. M. Johansson and H. Rensmo, J. Phys. Chem. Lett., 2014, 5, 648.

56. W. Hao, X. D. Chen and S. Z. Li, J. Phys. Chem. C, 2016, 120, 28448.

57. L. M. She, M. Z. Liu and D. Y. Zhong, ACS Nano, 2015, 10, 1126.

58. C. Quarti, F. De Angelis and D. Beljonne, Chem. Mater., 2017, 29, 958.

59. W. Geng, C. J. Tong, Z. K. Tang, C. Y. Yam, Y. N. Zhang, W.-M. Lau and L. M. Liu, J. Materiomics, 2015, 1, 213.

60. J. Haruyama, K. Sodeyama, L. Y. Han and Y. Tateyama, Accounts Chem. Res., 2016, 49, 554.

61. J. Haruyama, K. Sodeyama, L. Y. Han and Y. Tateyama, J. Phys. Chem. Lett., 2014, 5, 2903.

62. Q. Teng, T. T. Shi, R. Y. Tian, X. B. Yang and Y. J. Zhao, J. Solid State Chem., 2018, 258, 488.

63. M. M. Tavakoli, P. Yadav, R. Tavakoli and J. Kong, Adv. Energy Mater., 2018, 8, 1800794.

64. A. Vittadini, A. Selloni, F. P. Rotzinger and M. Grätzel, Phys. Rev. Lett., 1998, 81, 2954.

65. F. De Angelis, C. Di Valentin, S. Fantacci, A. Vittadini and A. Selloni, Chem. Rev., 2014, 114, 9708.

66. A. Vittadini, M. Casarin and A. Selloni, Theor. Chem. Acc., 2007, 117, 663.

67. Y. N. Hao, T. W. Chen, X. Zhang, H. Zhou and Y. C. Ma, J. Chem. Phys., 2019, 150, 224702.

68. A. Selloni, Nature Mater, 2008, 7, 613.

69. T. Kamachi, T. Tatsumi, T. Toyao, Y. Hinuma, Z. Maeno, S. Takakusagi, S. Furukawa, I. Takigawa and K.-I. Shimizu, J. Phys. Chem. C, 2019, 123, 20988.

70. E. Mosconi, E. Ronca and F. De Angelis, J. Phys. Chem. Lett., 2014, 5, 2619.

71. S. Colella, , E. Mosconi, P. Giovanna, A. Alberti, V. L. P. Guerra, S. Masi, A. Listorti, A. 
Rizzo, G. G. Condorelli, F. De Angelis and G. Gigli, J. Phys. Chem. Lett., 2014, 5, 3532.

72. W. Geng, C. J. Tong, J. Liu, W. J. Zhu, W.-M. Lau and L. M. Liu, Sci. Rep., 2016, 6, 20131.

73. R. Dovesi, A. Erba, R. Orlando, C. M. Zicovich-Wilson, B. Civalleri, L. Maschio, M. Rérat, S. Casassa, J. Baima, S. Salustro and B. Kirtman, WIRES Comput. Mol. Sci., 2018, 8, e1360.

74. R. Dovesi, V. R. Saunders, C. Roetti, R. Orlando, C. M. Zicovich-Wilson, F. Pascale, B. Civalleri, K. Doll, N. M. Harrison and I. Bush, Crystal06, 2006.

75. A. Erba, J. Baima, I. Bush, R. Orlando and R. Dovesi, J. Chem. Theory Comput., 2017, 13, 5019.

76. C. Adamo and V. Barone, J. Chem. Phys., 1999, 110, 6158.

77. F. Labat, P. Baranek, C. Domain, C. Minot and C. Adamo, J. Chem. Phys., 2007, 126, 154703.

78. S. Grimme, J. Comput. Chem., 2006, 27, 1787.

79. J. C. Barthelat, Ph. Durand and A. Serafini, Mol. Phys., 1977, 33, 159.

80. J. Berthelat and P. Durand, Gazz. Chim. Ital., 1978, 108, 225.

81. B. Metz, H. Stoll and M. Dolg, J. Chem. Phys., 2000, 113, 2563.

82. C. Ricca, A. Ringuedé, M. Cassir, C. Adamo and F. Labat, J. Phys. Chem. C, 2019, 123, 12573

83. D. M. Newns, Phys. Rev., 1969, 178, 1123.

84. F. Labat, I. Ciofini and C. Adamo, J. Mater. Chem., 2012, 22, 12205.

85. P. Persson, M. J. Lundqvist, R. Ernstorfer, W. Goddard and F. Willig, J. Chem. Theory Comput., 2006, 2, 441.

86. J. Haruyama, K. Sodeyama, I. Hamada, L. Y. Han and Y. Tateyama, J. Phys. Chem. Lett., $2017, \mathbf{8}, 5840$.

87. A. Marchioro, J. C. Brauer, J. Teuscher, M. Grätzel and J.-E. Moser, Physical Chemistry of Interfaces and Nanomaterials XII, International Society for Optics and Photonics, 2013, 881108

88. C. S. Ponseca Jr, T. J. Savenije, M. Abdellah, K. B. Zheng, A. Yartsev, T. Pascher, T. Harlang, P. Chabera, T. Pullerits, A. Stepanov, J.-P. Wolf, V. Sundström, J. Am. Chem. Soc., 2014, 136, 5189.

89. C. S. Ponseca Jr and V. Sundström, Nanoscale, 2016, 8, 6249. 